\title{
BETA- AND GAMMA-SYNUCLEINS MODULATE SYNAPTIC VESICLE-BINDING OF ALPHA-SYNUCLEIN
}

Kathryn E. Carnazza ${ }^{1 \#}$, Lauren Komer ${ }^{1 \#}$, André Pineda ${ }^{1}$, Yoonmi Na ${ }^{1}$, Trudy Ramlall², Vladimir L. Buchman ${ }^{3}$, David Eliezer², Manu Sharma1, Jacqueline Burré1,*

${ }^{1}$ Helen and Robert Appel Alzheimer's Disease Research Institute, Brain and Mind Research Institute, Weill Cornell Medicine, New York, New York 10021, USA.

2Department of Biochemistry, Weill Cornell Medicine, New York, New York 10021, USA.

${ }^{3}$ School of Biosciences, Cardiff University, Cardiff CF103AX, UK \& Institute of Physiologically Active Compounds Russian Academy of Sciences (IPAC RAS), Chernogolovka 142432, Moscow Region, Russian Federation.

\#These authors contributed equally to this work.

*Correspondence: jab2058@med.cornell.edu 


\section{SUMMARY}

$\alpha$-Synuclein ( $\alpha$ Syn), $\beta$-synuclein ( $\beta S y n)$, and $\gamma$-synuclein ( $\gamma S y n)$ are abundantly expressed in the vertebrate nervous system. aSyn functions in neurotransmitter release via binding to and clustering synaptic vesicles and chaperoning of SNARE-complex assembly. The functions of $\beta$ Syn and $\gamma$ Syn are unknown. Functional redundancy of the three synucleins and mutual compensation when one synuclein is deleted have been proposed, but with conflicting evidence. Here, we demonstrate that $\beta$ Syn and $\gamma$ Syn have a reduced affinity towards membranes compared to aSyn, and that direct interaction of $\beta$ Syn or $\gamma$ Syn with aSyn results in reduced membrane binding of $\alpha$ Syn. Our data suggest that all three synucleins affect synapse function, but only aSyn mediates the downstream function of vesicle clustering and SNARE-complex assembly, while $\beta$ Syn and $\gamma$ Syn modulate the activity of $\alpha$ Syn through regulating its binding to synaptic vesicles. 


\section{INTRODUCTION}

$\alpha$-Synuclein ( $\alpha$ Syn), $\beta$-synuclein ( $\beta$ Syn) and $\mathrm{y}$-synuclein ( $\gamma$ Syn) are abundantly expressed proteins in the vertebrate nervous system (Buchman et al., 1998b; George, 2002; Jakes et al., 1994; Ji et al., 1997; Lavedan et al., 1998; Nakajo et al., 1993). aSyn plays an important physiological role at the synapse, to maintain neurotransmitter release via binding to synaptic vesicles (Iwai et al., 1995; Kahle et al., 2000; Maroteaux et al., 1988), regulating synaptic vesicle pools (Cabin et al., 2002; Murphy et al., 2000; Yavich et al., 2004), and by chaperoning of SNARE-complex assembly (Burré et al., 2010). Aggregation of aSyn is a pathological hallmark of Parkinson's disease, Lewy body dementia, multiple system atrophy, and a variety of other synucleinopathies (Spillantini et al., 1997). Despite the involvement of $\beta$ Syn and $\gamma$ Syn in some neurodegenerative diseases including Lewy body dementia, diffuse Lewy body disease, Gaucher's disease, and Parkinson's disease (Galvin et al., 2000; Galvin et al., 1999; Nguyen et al., 2011; Ninkina et al., 2009; Nishioka et al., 2010; Peters et al., 2012; Surgucheva et al., 2002), virtually nothing is known about their physiological functions in the brain.

The three synucleins share a high degree of sequence homology (Jakes et al., 1994; Nakajo et al., 1993), are highly expressed in the human brain and show a strikingly similar regional distribution. Synucleins are coexpressed in the cerebral cortex, amygdala, caudate nucleus, substantia nigra, striatum, hippocampus, and thalamus (Ahmad et al., 2007; Jeannotte et al., 2009; Lavedan, 1998; Lavedan et al., 1998; Murphy et al., 2000; Ninkina et al., 1998), while in other brain areas, their expression patterns differ. For example, the subthalamic nucleus expresses mainly ySyn whereas the corpus callosum has aSyn and $\gamma$ Syn, but no $\beta$ Syn (Lavedan, 1998). In regions where co-expression occurs, the relative levels of synucleins differ. Evolutionarily recent regions express predominantly $\alpha$ Syn and $\beta$ Syn, whereas more ancient structures have higher levels of үSyn expression (Buchman et al., 1998b; Jakes et al., 1994; Jakowec et al., 2001; Lavedan, 1998; Maroteaux and Scheller, 1991; Ueda et al., 1993; Ueda et al., 1994). aSyn is most abundant in the frontal cortex, hippocampus, olfactory bulb, thalamus, and striatum (Iwai et al., 1995), while less aSyn is found in the more caudal regions, such as brainstem and spinal cord. In contrast, $\beta$ Syn is predominantly expressed in the neocortex, hippocampus, striatum, thalamus, and cerebellum (George, 2002). In the brain, highest expression of ySyn is found in the substantia nigra, hippocampus, thalamus, caudate nucleus, amygdala, and particularly, the motor nuclei of the brain stem (Buchman et al., 1998b; Ji et al., 1997; Lavedan et al., 1998).

These expression patterns suggest that each synuclein may partake in a distinct function, as suggested by some studies, although functional redundancy has been proposed as well. A compensatory function is supported by increased expression of the remaining family member in the CNS of $\alpha / \beta-S y n$ and $\alpha / \gamma-S y n$ double knockout mice (Chandra et al., 2004; Robertson et al., 2004), and accelerated pathology in CSPa knockout mice in the absence of both $\alpha$ Syn and $\beta$ Syn compared to $\alpha$ Syn only (Chandra et al., 2005). Functional redundancy is supported by a behavioral and dopamine release phenotypes in $\alpha / \gamma$-Syn knockout mice while single aSyn KO or үSyn KO mice showed no deficits (Senior et al., 2008), by considerable functional overlap in 
the pools of genes whose expression is changed in the absence of aSyn or ySyn (Kuhn et al., 2007), and by a decrease in dopamine levels in brains of $\alpha / \beta$-Syn KO but not $\alpha$ Syn or $\beta$ Syn single KO (Chandra et al., 2004).

In contrast, other studies found no compensatory increase in aSyn or $\beta$ Syn expression upon knockout of $\gamma$ Syn (Ninkina et al., 2003; Papachroni et al., 2005), in ßSyn upon knockout of aSyn and үSyn (Papachroni et al., 2005), or in $\beta$ Syn or $\gamma$ Syn upon aSyn knockout (Abeliovich et al., 2000; Kuhn et al., 2007; Schluter et al., 2003). Lack of compensation was also surmised from lack of exaggeration of phenotypes in $\alpha / \gamma$-Syn double KO mice compared to aSyn and ySyn single KO mice (Robertson et al., 2004). Redundancy was countered by lack of potentiation of gene expression in $\alpha / \gamma-S y n$ knockout versus $\alpha$ Syn and $\gamma$ Syn single knockout mice and differentially regulated gene expression in aSyn and үSyn KO mice (Kuhn et al., 2007), and a reduction in striatal dopamine and specific protein levels in aSyn null but not үSyn null mice (Al-Wandi et al., 2010), a lack of ySyn ability to interact with VAMP2, support SNARE-complex assembly and rescue the CSPa knockout phenotype (Ninkina et al., 2012), as well as a distinct effect of the lack of only $\beta$ Syn in an inverted grid test, and a distinct effect of the lack of only aSyn on striatal dopamine levels that was not exacerbated by additional loss of the other synucleins (Connor-Robson et al., 2016). These discrepancies may be either due to the fact that different brain regions and different animal ages were analyzed in these studies, or they may point to a different role of the three synucleins in the same cellular process.

Here, we demonstrate the first important physiological function for $\beta$ Syn and $\gamma S y n$ that can explain and consolidate the seemingly controversial findings above. Our data support a model where all synuclein family members affect synapse function, but their specific roles in that process differ, in that only aSyn mediates the downstream function of vesicle clustering and SNARE-complex assembly while $\beta$ Syn and $\gamma$ Syn modulate the activity of aSyn through regulating its binding to synaptic vesicles.

\section{RESULTS}

\section{$\beta$ Syn and $y$ Syn reveal reduced $\alpha$-helical content and binding to liposomes compared to $\alpha$ Syn}

aSyn binds to synaptic vesicle membranes (Iwai et al., 1995; Kahle et al., 2000; Maroteaux et al., 1988), reflecting its preference for membranes with high curvature (Davidson et al., 1998; Middleton and Rhoades, 2010). $\beta S y n$ and $\gamma$ Syn share the highly conserved $\alpha$-helical lipid-binding motif with aSyn (Figure S1A), and can adopt the same two-helix conformation (Rivers et al., 2008; Sung and Eliezer, 2006), suggesting that they bind to lipids as well. Yet, the lipid binding domain of $\beta$ Syn shares only $87 \%$ sequence identity with $\alpha$ Syn and lacks 11 residues toward the end, and $\gamma$ Syn shares only 68\% sequence identity in the lipid binding domain (Figure $\mathrm{S} 1 \mathrm{~A})$. These differences may lead to different membrane binding properties.

When we analyzed the ability of $\alpha$ Syn, $\beta$ Syn, or $\gamma$ Syn to associate with artificial liposomes of 30 nm diameter in a flotation assay (Figure S1B), we found robust binding of aSyn to liposomes composed of $30 \%$ phosphatidylserine and $70 \%$ phosphatidylcholine, as well as to liposomes mimicking synaptic vesicles (Figure $1 \mathrm{~A}$; Figure S1C). Strikingly, $\beta$ Syn and $\gamma$ Syn revealed a dramatically reduced binding to both of these 
liposomes, which was not affected by deletion of the C-termini that are not important for the interaction with membranes (Figure 1A; Figure S1C-E).

aSyn preferentially associates with liposomes of high curvature (Davidson et al., 1998; Middleton and Rhoades, 2010), but $\beta$ Syn and $\gamma$ Syn may have a preference for less curved membranes. We thus repeated our flotation assay in presence of liposomes of $100 \mathrm{~nm}$ (Figure S1D) or $200 \mathrm{~nm}$ (Figure S1E) diameter, but lost binding of all synucleins to these larger liposomes.

Last, aSyn, $\beta$ Syn, and $ү S y n$ may have different affinities and thus potentially different saturation levels towards liposomes. We thus tested binding of synucleins to liposomes at different molar lipid:protein ratios, extending beyond the known saturation levels for aSyn (Figure 1B and 1C). We found saturation of binding of all synuclein family members around a molar lipid:protein ratio of 400 . Strikingly, $\beta$ Syn and $\gamma$ Syn binding plateaued at a significantly lower liposome-bound protein percentage compared to aSyn (Figure 1B and 1C).

aSyn is natively unstructured in solution, but adopts an a-helical conformation upon binding to membranes (Burre et al., 2013; Davidson et al., 1998; Iwai et al., 1995; Kahle et al., 2000; Maroteaux et al., 1988). Thus, as a separate means to assess binding of synucleins to liposomes, we used circular dichroism (CD) spectroscopy. While all synucleins had a similar unfolded nature in solution (Figure 1D), $\beta$ Syn and $\gamma S y n$ revealed reduced $\alpha$-helicity at all molar lipid:protein ratios tested (Figure 1E and 1F). These data are in agreement with our liposome flotation data (Figure 1A-C; Figure S1) and suggest that $\beta$ Syn and $\gamma$ Syn have significantly reduced affinities towards membranes compared to aSyn.

These data suggest a reduced ability of $\beta$ Syn and $\gamma$ Syn to associate with phospholipid membranes, which is in agreement with the literature reporting a reduced propensity of $\beta$ Syn for $\alpha$-helical secondary structure in the $N$ terminal region compared to aSyn (Bertoncini et al., 2007; Sung and Eliezer, 2006), a five-fold lower affinity of $\beta$ Syn binding to DMPS vesicles relative to aSyn (Brown et al., 2016), a two-fold lower affinity for $\beta$ Syn and YSyn binding to 1:1 POPC:POPS vesicles relate to aSyn (Ducas and Rhoades, 2012; Middleton and Rhoades, 2010), and a reduced binding affinity of $\beta$ Syn to POPA:POPC vesicles compared to aSyn (Sharma et al., 2020).

\section{Reduced presynaptic localization of ySyn but not $\beta$ Syn compared to $\alpha$ Syn}

The flotation and CD experiments above used purified recombinant synucleins and phospho-liposomes. To probe for membrane binding in a more physiological context, we performed subcellular fractionation on wildtype (WT) mouse brains to separate brain homogenate into cytosolic and membrane-bound fractions. We found the integral membrane protein VDAC1 and membrane-associated protein SNAP-25 to be robustly associated with membrane fractions, demonstrating successful fractionation (Figure S2A). Synucleins were more cytosolic, representative of their on/off membrane equilibrium. Compared to aSyn, we found a significant reduction in membrane-bound $\beta$ Syn and $\gamma$ Syn, with $\alpha$ Syn $>\gamma$ Syn $>\beta S y n$ detected in the bound fraction (Figure S2). 
aSyn targets to presynaptic terminals via binding to synaptic vesicle membranes (Iwai et al., 1995; Kahle et al., 2000; Maroteaux et al., 1988) and to the synaptic vesicle protein synaptobrevin-2/VAMP2 (Burre et al., 2012;

Burré et al., 2010). Subcellular compartment-specific membrane and/or protein interactions may thus affect the synaptic localization of all synucleins. We thus enriched for synaptosomes from brain homogenates of WT mice and analyzed relative synuclein levels in synaptosomes. We found an enrichment for the synaptic vesicle proteins synaptobrevin-2 and CSPa, while $\alpha$-tubulin and neurofilament of $165 \mathrm{kDa}$ were depleted, as expected (Figure 2A and 2B). When we analyzed the synucleins, we found neither enrichment nor depletion of $\alpha$ Syn and $\beta S y n$ in synaptosomes compared to brain homogenates, while $\gamma$ Syn showed a significant depletion in synaptosomes compared to total brain homogenate (Figure $2 \mathrm{~A}$ and $2 \mathrm{~B}$ ). In parallel, we analyzed the synaptic colocalization of $\alpha$ Syn, $\beta S y n$ or $\gamma S y n$ with the synaptic marker synapsin in primary cortical WT mouse neurons. We found a robust synaptic localization for $\alpha$ Syn and $\beta$ Syn, similar to the integral synaptic vesicle proteins SV2 and synaptobrevin-2, while ySyn was not as synaptic (Figure 2C-E). These findings agree with the reported presynaptic localization for $\alpha$ Syn and $\beta$ Syn, and the more widely dispersed localization for $\gamma$ Syn throughout the cytosol (Buchman et al., 1998a; Buchman et al., 1998b; Jakes et al., 1994; Maroteaux et al., 1988; Mori et al., 2002; Murphy et al., 2000; Surguchov et al., 2001).

\section{Synucleins interact with each other in a specific conformation}

Despite a dramatically reduced ability to associate with membranes compared to aSyn, how do $\beta$ Syn and, to a lesser extent, ySyn, still target to the synapse? Based on our previous studies showing homo-multimerization of the membrane-binding domain of aSyn (Burre et al., 2014), synucleins may interact with each other, thereby enabling synaptic co-localization. In fact, there is precedence for a possible in vivo interaction among the synuclein family members in the literature, although mainly focused on inhibition of aSyn aggregation by $\beta S y n$ or YSyn (Biere et al., 2000; Hashimoto et al., 2001; Park and Lansbury, 2003; Uversky et al., 2002; Windisch et al., 2002): (1) $\beta$ Syn affects the speed of the nucleation phase of aSyn during in vitro fibrillation (Brown et al., 2016; Van de Vondel et al., 2018), (2) aSyn/ßSyn heterodimers were found in yeast (Tenreiro et al., 2016), (3) NMR PRE titration experiments measured a Kd for the $\alpha$ Syn/ $\beta$ Syn heterodimer of $100 \mu \mathrm{M}$, while the aSyn/aSyn homodimer Kd's were $500 \mu \mathrm{M}$ (Janowska et al., 2015), (4) molecular dynamics and potential of mean force computational study found that it is more favorable for aSyn to complex with $\beta$ Syn to form heterodimers, rather than a second aSyn to form homodimers (Sanjeev and Mattaparthi, 2017; Tsigelny et al., 2007), and (6) weak to moderate $\mu \mathrm{M}$ binding affinities were found for $\alpha$ Syn- $\beta S y n, \beta S y n-\gamma S y n$, and $\alpha$ Syn- $\gamma$ Syn, with the aSyn- $\beta$ Syn interaction being the weakest (Jain et al., 2018).

When we probed directly for interactions among the synuclein family members using co-immunoprecipitation in absence of membranes, we did not detect any binding (Figure S3A). Given that multimers of aSyn only form upon membrane binding of aSyn (Burre et al., 2014), aSyn- $\beta$ Syn and $\alpha$ Syn- $\gamma$ Syn interactions may require membranes as well. Yet, immunoprecipitation in presence of membranes is complicated by non-specific binding and thus not feasible. We thus adapted our FRET system that we had previously used to assess the specific 
configuration of aSyn multimers on membranes (Burre et al., 2014). For this, we introduced cysteine residues at the beginning and the end of the $\alpha$-helical domains of the synucleins, generated recombinant proteins, and labeled these cysteines either with Alexa488 or Alexa546 (Figure 3A). Based on our previous studies (Burre et al., 2014), we assumed that not only homo-multimers but also hetero-multimers of synucleins would adopt the antiparallel broken helix configuration (Fig. 3B), and thus labeled only residues within the synucleins that match this configuration (Fig. 3A, B). We then measured FRET between various combinations in presence or absence of liposomes (Figure 3C, D; Figure S3). Only in presence of charged liposomes did we detect a FRET signal between $\alpha$ Syn, $\beta$ Syn or $\gamma S y n$, suggesting that all synucleins share the ability to form homo-dimers (Figure 3C). As expected, we were unable to detect any FRET signal between synucleins in presence of neutral liposomes that synucleins do not bind to. Importantly, our FRET experiments also provide evidence for heteromultimerization between the synucleins in the presence of membranes (Figure 3D).

\section{Synucleins modulate each other's ability to associate with membranes}

Does hetero-multimerization of synucleins have a functional consequence? For physiological implications of this interaction, synucleins need to be expressed in the same neuron. When we tested if aSyn is co-expressed with $\beta$ Syn or $\gamma S y n$ in wild-type neurons, we found $\beta$ Syn to highly co-localize with aSyn in presynaptic compartments (indicated by individual puncta), while the overlap of $\gamma$ Syn with aSyn was largely restricted to dendritic and somatic compartments (Figure S4A and S4B). Note that not all presynaptic terminals stain equally strong for each of the synucleins, indicating heterogeneity in synucleins levels in different neurons.

We then analyzed if presence or absence of $\beta$ Syn or $\gamma$ Syn results in changes in the synaptic targeting of $\alpha$ Syn, using co-expression via lentiviral vectors in $\alpha \beta \gamma$-synuclein triple knockout neurons. When we quantified synaptic targeting of $\alpha$ Syn with increasing levels of $\beta$ Syn or $\gamma$ Syn, we found a significant dose-dependent reduction in synaptic localization of aSyn (Figure 4A-D; Figure S4C-F).

In parallel, to test synaptic targeting at endogenous expression levels, we generated single $\alpha$ Syn, $\beta$ Syn, and ySyn knockout mice from our aßy-synuclein triple knockout mice (Figure S5A and S5B). We then repeated the analysis of synaptic targeting of $\alpha$ Syn, $\beta$ Syn, and $\gamma$ Syn using a synaptosome enrichment study. When we compared the relative amount of synucleins in synaptosomes versus total brain, we found a significantly increased amount of synaptic aSyn in absence of $\beta$ Syn or $\gamma$ Syn (Figure 4E and 4F), unlike in WT brains (Figure 2A). Importantly, this was neither due to changes in efficiency of subcellular fractionation, as marker proteins revealed the same enrichment and depletion as in wild-type brains (Figure 2A and 2B, and Figure S5C.E), nor was it due to altered expression levels of synucleins in these genotypes (Figure S5A and S5B).

To test directly if $\beta$ Syn and $\gamma$ Syn reduce the ability of $\alpha$ Syn to associate with synaptic vesicle membranes, we measured liposome binding of aSyn in absence or presence of equal amounts of $\beta$ Syn or $\gamma$ Syn and vice versa using a liposome flotation assay. Interestingly, we found a significant reduction in membrane association of $\alpha$ Syn in presence of $\beta$ Syn or $\gamma$ Syn (Figure $4 \mathrm{G}$ and $4 \mathrm{H}$ ), and an increase in membrane association of $\beta$ Syn and 
YSyn when aSyn was present (Figure S5F and S5G), suggesting that synucleins directly affect each other's ability to bind to synaptic vesicle membranes.

Overall, our data suggest that via hetero-multimerization, the largely cytosolic $\beta$ Syn and $\gamma$ Syn reduce the amount of synaptic vesicle-bound aSyn, potentially providing a tuning mechanism for aSyn function in synaptic vesicle clustering and neurotransmitter release (Figure $4 \mathrm{H}$ ).

\section{DISCUSSION}

The function of aSyn is tightly linked to its localization in presynaptic terminals. Targeting of aSyn to terminals is mediated by binding to synaptic vesicle lipids and synaptobrevin-2 (Burré et al., 2010; Iwai et al., 1995; Kahle et al., 2000; Maroteaux et al., 1988; Sun et al., 2019), and binding to vesicles triggers multimerization of aSyn which in concert with binding of aSyn to synaptobrevin-2, promotes synaptic vesicle clustering (Diao et al., 2013; Sun et al., 2019). The implications of this clustering activity have been suggested to restrict synaptic vesicle mobility between synapses (Scott and Roy, 2012) and to serve as a reserve pool of synaptic vesicles for long-term operation of a neuron during high-frequency stimulation (Diao et al., 2013). In agreement, loss of synucleins increases tethering of synaptic vesicles to the active zone and reduces links between vesicles (Vargas et al., 2017), while interlocked aSyn/synaptobrevin-2 dimers reduce dispersion (Sun et al., 2019). In addition, $\mathrm{Ca}^{2+}$ has been suggested to regulate the interaction of aSyn with synaptic vesicles (Lautenschlager et al., 2018), and electron microscopy studies show a redistribution of aSyn with activity (Tao-Cheng, 2006).

Here, we have identified a new control mechanism for synaptic vesicle-binding of aSyn (Figure $4 \mathrm{H}$ ). The physiological functions of $\beta S y n$ and $\gamma$ Syn have remained largely elusive, although a neuroprotective role for both has been proposed (da Costa et al., 2003; Hashimoto et al., 2001; Windisch et al., 2002), suggesting that interactions among synucleins are important and need to be examined. We demonstrate here that $\beta$ Syn and үSyn have a direct effect on the physiologically functional pool of aSyn on synaptic vesicles, suggesting that the roles of synucleins are complementary, but not functionally redundant, which may explain some of the controversial findings in the field. How is this process regulated within a presynaptic terminal where two or three synucleins co-localize? The decrease of aSyn interaction with the synaptic vesicle membrane could be due to direct competition of the synucleins for binding sites on the synaptic vesicle membrane. In this case, more aSyn would bind to the vesicle surface in neurons lacking $\beta S y n$ or $\gamma$ Syn due to lack of competition. However, $\beta$ Syn and $\gamma$ Syn reveal a reduced binding affinity towards membranes (Figures 1 and 2 ), so unless there is an excess amount of $\beta S y n$ or $\gamma S y n$ in a terminal, there may not be significant competition. In addition, presence of $\alpha$ Syn increases membrane binding of $\beta$ Syn and $\gamma$ Syn (Figure S5), which also argues against competition. As an alternative mechanism, binding of $\beta$ Syn or $\gamma$ Syn to aSyn on the synaptic vesicle surface may reduce the affinity of aSyn for synaptic vesicle membranes, either by interfering with the aSyn-membrane interaction directly, or by reducing the overall binding affinity of aSyn for membranes through the formation of heteromers. Regardless of the specific mechanism, our findings raise several important questions that are 
essential for our understanding of synuclein biology and pathology and will need to be addressed in follow-up studies:

The synucleins are co-expressed at varied levels in the brain (Buchman et al., 1998b; George, 2002; Iwai et al., 1995; Jakes et al., 1994; Jakowec et al., 2001; Ji et al., 1997; Lavedan, 1998; Lavedan et al., 1998; Maroteaux and Scheller, 1991; Ueda et al., 1993; Ueda et al., 1994), and single cell RNA seq analysis of mouse cortex and hippocampus reveals expression ratios of $\alpha$ Syn/ $\beta$ Syn between $0.64-2.3$, with the majority between 1-1.5, and $\alpha$ Syn/ySyn ratios between 1.1-1.85, with a lack of detection of $\gamma$ Syn in most cells (Allen Institute for Brain Science)(Hawrylycz et al., 2012; Lein et al., 2007). In agreement, analyses of human cortex reveals expression ratios of $\alpha$ Syn/ $\beta$ Syn between 0.002-6.31, with the majority between $1-1.5$, and $\alpha$ Syn/ $/$ Syn ratios between 0.088-362, also with a lack of detection of $y$ Syn in most cells (Allen Institute for Brain Science) (Hawrylycz et al., 2012; Lein et al., 2007). This vast heterogeneity suggests that relative ratios of $\alpha$ Syn, $\beta$ Syn, and $y$ Syn could modulate synaptic vesicle clustering and SNARE-complex assembly and thus neuron function via regulating the relative amount of $\alpha$ Syn on synaptic vesicles. $\alpha$ Syn has been shown to disperse from the nerve terminal in response to neural activity (Fortin et al., 2005). Furthermore, expression of $\alpha$ Syn is high in regions of the adult CNS that display synaptic plasticity (Maroteaux and Scheller, 1991), and in adult canaries and zebra finches, where aSyn expression correlates with plasticity in the developing song control system (Clayton and George, 1999). At present, it remains to be determined whether plastic regions in the brain feature altered expression levels of $\alpha$ Syn, $\beta$ Syn, and $ү S y n$.

Besides identifying a new physiological function for $\beta$ Syn and $\gamma$ Syn, our findings may also have implications for the contributions of $\beta S y n$ and $\gamma$ Syn to disease. $\beta$ Syn and $\gamma$ Syn have links to Lewy body dementia, diffuse Lewy body disease, Gaucher's disease, motor neuron disease, neurodegeneration with brain iron accumulation type 1, glaucoma, and Parkinson's disease (Galvin et al., 2000; Galvin et al., 1999; Nguyen et al., 2011; Ninkina et al., 2009; Nishioka et al., 2010; Peters et al., 2012; Surgucheva et al., 2002). We and others have previously shown that lack of SNARE chaperoning by aSyn or the CSPa chaperone complex causes progressive neuropathology and premature death (Burre et al., 2012, 2015; Burré et al., 2010; Greten-Harrison et al., 2010; Sharma et al., 2012; Sharma et al., 2011), and synuclein triple knockout mice exhibit an age- and activitydependent decrease in SNARE-complex assembly which correlates with progressive neuropathology and leads to premature death (Burré et al., 2010). Thus, aSyn is required for the long-term sustenance of nerve terminals and neurons and protects against age-dependent decline by ensuring SNARE-complex assembly over the long life of a neuron. Rendering aSyn less membrane-associated through the presence of $\beta$ Syn and YSyn may increase the aggregation-prone cytosolic pool of aSyn. Alternatively, binding of aSyn to $\beta$ Syn or to үSyn may shield the aggregation-prone residues in aSyn. The relative ratios of the three synucleins may explain the selective vulnerability of certain neuronal populations to dysfunction and degeneration.

Finally, our findings may point to an alternative therapeutic strategy by adjusting not only aSyn levels, but focusing on $\beta$ Syn and $\gamma$ Syn levels as well. Previous strategies have concentrated largely on eliminating $\alpha$ Syn 
from the brain. Yet, removal of aSyn can cause functional changes to neuronal synapses in various in vivo experimental systems, particularly in the aged nervous system (Al-Wandi et al., 2010; Benskey et al., 2018; Collier et al., 2016; Gorbatyuk et al., 2010; Markopoulou et al., 2014; Ninkina et al., 2020; Robertson et al., 2004), and strategies targeting $\beta$ Syn or $\gamma$ Syn to alter aggregation-prone pools of $\alpha$ Syn may be less detrimental.

In summary, our data suggest that a correct balance of synucleins is important for normal brain function, and that an imbalance of these proteins might not only affect neuron function and plasticity, but also neuronal survival.

\section{METHODS}

Mouse strains: WT and synuclein null mice were maintained on a C57BL/6 background. Synuclein triple knockout mice were maintained as described previously (Burré et al., 2010). aSyn, $\beta$ Syn and $\gamma$ Syn single knockout mouse lines were generated by crossing the synuclein triple knockout mice to wild type C57BL/6 mice, and then back crossing the triple-hemizygous progeny to wild type progeny for 5 generations, before separating each of the synuclein knockout alleles. Mice of either sex were used for primary neuronal culture, and no inclusion criteria were used. Mice were housed with a 12-h light/dark cycle in a temperature-controlled room with free access to water and food. All animal procedures were performed according to $\mathrm{NIH}$ guidelines and approved by the Committee on Animal Care at Weill Cornell Medicine.

Cell culture and maintenance: HEK293T cells (ATCC) were maintained in DMEM with 1\% penicillin and streptomycin and $10 \%$ bovine serum. For production of lentiviral vectors, cells were transfected with equimolar amounts of lentiviral vector FUW containing myc-tagged or untagged $\alpha$ Syn, $\beta$ Syn or $\gamma$ Syn, pMD2-G-VSVg, pMDLg/pRRE, and pRSV-Rev using calcium phosphate produced in house. $1 \mathrm{~h}$ prior to transfection, $25 \mu \mathrm{M}$ chloroquine in fresh media was added. DNA was incubated for $1 \mathrm{~min}$ at room temperature in $100 \mathrm{mM} \mathrm{CaCl}_{2}$ and $1 \times$ HBS (25 mM HEPES pH 7.05, $140 \mathrm{mM} \mathrm{NaCl}$, and $0.75 \mathrm{mM} \mathrm{Na}_{2} \mathrm{HPO}_{4}$ ) and the transfection mix was then slowly added to the cells. Medium was replaced with fresh medium after $6 \mathrm{~h}$. Medium containing the viral particles was collected $48 \mathrm{~h}$ later and centrifuged for $10 \mathrm{~min}$ at $500 \mathrm{gav}_{\mathrm{av}}$ to remove cellular debris. Viral particles were subsequently concentrated tenfold by centrifugation. Mouse cortical neurons were cultured from newborn mice of either sex. Cortices were dissected in ice-cold HBSS, dissociated and triturated with a siliconized pipette, and plated onto $6 \mathrm{~mm}$ poly I-lysine-coated coverslips (for immunofluorescence) or on 24-well plastic dishes. Plating media (MEM supplemented with $5 \mathrm{~g} / \mathrm{l}$ glucose, $0.2 \mathrm{~g} / \mathrm{l} \mathrm{NaHCO}, 0.1 \mathrm{~g} / \mathrm{l}$ transferrin, $0.25 \mathrm{~g} / \mathrm{l}$ insulin, $0.3 \mathrm{~g} / \mathrm{l}$ l-glutamine, and $10 \%$ fetal bovine serum) was replaced with growth media (MEM containing $5 \mathrm{~g} / \mathrm{l}$ glucose, $0.2 \mathrm{~g} / \mathrm{l} \mathrm{NaHCO}_{3}, 0.1 \mathrm{~g} / \mathrm{l}$ transferrin, $0.3 \mathrm{~g} / \mathrm{l}$ l-glutamine, 5\% fetal bovine serum, $2 \%$ B-27 supplement, and $2 \mu \mathrm{M}$ cytosine arabinoside) 2 days after plating. At 6 days in vitro (DIV), neurons were transduced with recombinant lentiviruses expressing synucleins. Neurons were harvested or used for experiments as indicated at 27 DIV. 
Immunoprecipitation: Transfected HEK293T cells were solubilized in PBS, pH 7.4, containing 0.15\% Triton X100 and protease inhibitors (Roche). Following centrifugation at $16,000 \mathrm{gav}_{\mathrm{av}}$ for $20 \mathrm{~min}$ at $4^{\circ} \mathrm{C}$, the clarified lysate was used for immunoblotting (after addition of 2x SDS sample buffer containing 100 mM DTT) or subjected to immunoprecipitation. Immunoprecipitation was performed with the indicated primary antibodies and $50 \mu \mathrm{l}$ of a $50 \%$ slurry of protein-A sepharose beads (GE Healthcare) for $2 \mathrm{~h}$ at $4{ }^{\circ} \mathrm{C}$. Control immunoprecipitations were performed with preimmune sera. Following five washes with $1 \mathrm{ml}$ of the extraction buffer, bound proteins were eluted with 2x SDS sample buffer containing $100 \mathrm{mM}$ DTT and boiled for $20 \mathrm{~min}$ at $100^{\circ} \mathrm{C}$. Coprecipitated proteins were separated by SDS-PAGE, with $5 \%$ of the input in the indicated lane.

Subcellular fractionation: For cytosol/membrane fractionations, entire mouse brains were homogenized in PBS containing protease inhibitors. The homogenates were centrifuged for $1 \mathrm{~h}$ at 300,000 $\mathrm{g}_{\mathrm{av}}$. The supernatant was collected and an equal volume of PBS was added to the pellet. Same volumes were analyzed via SDS-PAGE. Synaptosomes were isolated as previously described (Burre et al., 2006). Briefly, entire mouse brains were homogenized in preparation buffer $(5 \mathrm{mM}$ Tris- $\mathrm{HCl}, 320 \mathrm{mM}$ sucrose, $\mathrm{pH} 7.4)$, supplemented with protease inhibitors. The homogenate was centrifuged for $10 \mathrm{~min}$ at $1,000 \mathrm{gav}$. The supernatant was collected and the pellet was resuspended in preparation buffer and recentrifuged. Both supernatants were pooled and the final pellet was discarded. Discontinuous Percoll gradients were prepared by layering $7.5 \mathrm{ml}$ supernatant onto three layers of $7.5 \mathrm{ml}$ Percoll solution (3\%, 10\%, and 23\% v/v in $320 \mathrm{mM}$ sucrose, $5 \mathrm{mM}$ Tris- $\mathrm{HCl}, \mathrm{pH} 7.4)$. After centrifugation for $7 \mathrm{~min}$ at $31,400 \mathrm{gav}_{\mathrm{av}}$ fractions containing synaptosomes were collected, diluted in four volumes of preparation buffer and centrifuged for $35 \mathrm{~min}$ at $20,000 \mathrm{gav}_{\mathrm{av}}$

SDS-PAGE and quantitative immunoblotting: Protein samples were separated by SDS-PAGE and either stained using Coomassie Brilliant Blue, or transferred onto nitrocellulose membranes. Blots were blocked in Tris-buffered saline (TBS) containing $0.1 \%$ Tween-20 (TBS-T) containing 5\% fat-free milk for 30 min at room temperature. The blocked membrane was incubated overnight in PBS containing $1 \% \mathrm{BSA}$ and $0.2 \% \mathrm{NaN}_{3}$ and the primary antibody. The blots were then washed twice in TBS-T containing $5 \%$ fat-free milk, then incubated for $1 \mathrm{~h}$ in the same buffer containing secondary antibody at room temperature. Blots were then washed 3 times in TBS-T, twice in water, and then dried in the dark. Blots were imaged using a LI-COR Odyssey CLx, and images were analyzed using ImageStudioLite (LI-COR).

Antibodies: CSPa (R807, gift from Dr. Thomas C. Südhof), GAPDH (G-9, Santa Cruz), myc (9E10, deposited to the DSHB by Bishop, J.M.), VDAC1 (N152B/23, Neuromab), NF-165 (2H3, deposited to the DSHB by Jessell, T.M. / Dodd, J.), SNAP-25 (SMI81, Sternberger Monoclonals), synapsin (E028, gift from Dr. Thomas C. Südhof), synaptobrevin-2 (69.1, Synaptic Systems), aSyn (clone 42, BD Biosystems), $\beta$ Syn (sc-136452, Santa Cruz), ySyn (SK23 (Ninkina et al., 2003)), and a-Tubulin (12G10, DSHB).

Expression vectors: Full-length human $\alpha$ Syn, $\beta$ Syn or $\gamma$ Syn cDNA was inserted into modified pGEX-KG vectors (GE Healthcare), containing an N-terminal TEV protease recognition site, or lentiviral vector FUW, without or with an N-terminal myc-tag and a four amino acid linker, resulting in the following $\mathrm{N}$-terminal sequence 
(EQKLISEEDL-GSGS). Mutant aSyn, $\beta$ Syn, or $\gamma$ Syn constructs were generated by site-specific mutagenesis, according to the protocol of the manufacturer (Stratagene).

Recombinant protein expression and purification: All proteins were expressed as GST fusion proteins in bacteria (BL21 strain), essentially as described (Burré et al., 2010). Bacteria were grown to OD 0.6 (measured at $600 \mathrm{~nm}$ ), and protein expression was induced with $0.05 \mathrm{mM}$ isopropyl $\beta$-o-thiogalactoside for $6 \mathrm{~h}$ at room temperature. Bacteria were harvested by centrifugation for $20 \mathrm{~min}$ at 2,100 $\mathrm{g}$, and pellets were resuspended in solubilization buffer [PBS, $0.5 \mathrm{mg} / \mathrm{mL}$ lysozyme, $1 \mathrm{mM}$ PMSF, DNase, and an EDTA-free protease inhibitor mixture (Roche)]. Cells were broken by sonication, and insoluble material was removed by centrifugation for $30 \mathrm{~min}$ at $7,000 \mathrm{~g}_{\mathrm{av}}$ and $4{ }^{\circ} \mathrm{C}$. Proteins were affinity-purified using glutathione Sepharose bead (GE Healthcare) incubation overnight at $4{ }^{\circ} \mathrm{C}$, followed by TEV protease (Invitrogen) cleavage overnight at room temperature. His-tagged TEV protease was removed by incubation with Ni-NTA (Qiagen) overnight at $4{ }^{\circ} \mathrm{C}$. Protein concentrations were assessed using the bicinchoninic acid method according to the manufacturer's protocol (Thermo Scientific).

Liposome preparation and liposome binding assay: Liposomes were prepared as previously described (Burré et al., 2010). For lipid-binding assays, a mixture of lipids (all Avanti Polar Lipids) in chloroform were dried in a glass vial under a nitrogen stream. Residual chloroform was removed by lyophilization for $2 \mathrm{~h}$. Small unilamellar vesicles were formed by sonicating in PBS on ice. For lipid binding studies, synucleins were incubated with liposomes for $2 \mathrm{~h}$ at room temperature at a molar lipid/protein ratio of 400 or other ratios where indicated. For co-flotation experiments, $\alpha$ Syn, $\beta$ Syn and $\gamma$ Syn were added at a molar lipid/protein ratio of 200 each. Samples were then subjected to a liposome flotation assay (Burré et al., 2010).

FRET experiments. $100 \mu \mathrm{M}$ GST-fusion protein of $\alpha$ Syn, $\beta$ Syn or $\gamma$ Syn containing a cysteine (positions 8 and 96 for $\alpha$ Syn and $\gamma$ Syn, positions 8 and 85 for $\gamma S y n$ ) were captured on GS4B beads (GE Healthcare). GSTsynucleins were reduced with $1 \mathrm{mM}$ DTT for $20 \mathrm{~min}$ at $4{ }^{\circ} \mathrm{C}$. Beads were washed four times with PBS containing protease inhibitors and protein were labeled with 2 mM Alexa 488 C5 maleimide or Alexa 546 C5 maleimide (Invitrogen) overnight at $4{ }^{\circ} \mathrm{C}$ in the dark. Beads were washed four times with PBS to remove residual unbound dye, and synuclein was eluted from the GST moiety using TEV protease overnight at room temperature. His-tagged TEV protease was removed using Ni-NTA agarose (Qiagen). For FRET experiments, $2.5 \mu \mathrm{g}$ of Alexa 488-labeled donor synuclein and $2.5 \mu \mathrm{g}$ of Alexa 546-labeled acceptor synuclein were incubated with and without $100 \mu \mathrm{g}$ of liposomes in $100 \mu \mathrm{l}$ of PBS for $2 \mathrm{~h}$ at room temperature in the dark. Emission spectra were measured using a Synergy H1 plate reader (BioTek; excitation: 490 nm; emission: 500$650 \mathrm{~nm}$ ). FRET signals were measured by calculating ratios of RD+A (i.e. ratio of fluorescence of donor plus acceptor $\alpha$-synuclein at $573 \mathrm{~nm}$ and of fluorescence of donor plus acceptor $\alpha$-synuclein at $519 \mathrm{~nm}$, each subtracted by fluorescence of acceptor $\alpha$-synuclein) and RD (i.e., ratio of fluorescence of donor $\alpha$-synuclein at $573 \mathrm{~nm}$ and of fluorescence of donor a-synuclein at $519 \mathrm{~nm}$ ). 
Circular dichroism spectroscopy: Circular dichroism (CD) spectra were measured on an AVIV 62 DS spectrometer equipped with a sample temperature controller. Far-UV CD spectra were monitored from 190 to $300 \mathrm{~nm}$ using final protein concentrations of $50 \mu \mathrm{M}$ and $0.1 \mathrm{mM}$ to $15 \mathrm{mM}$ small unilamellar vesicles (composition: $70 \%$ phosphatidylcholine, 30\% phosphatidylserine; diameter: $\sim 30 \mathrm{~nm}$ ) with a path length of 0.2 $\mathrm{mm}$, response time of $1 \mathrm{~s}$, and scan speed of $50 \mathrm{~nm} / \mathrm{min}$. Each scan was repeated three times.

Immunocytochemistry: Cells were washed twice with phosphate-buffered saline (PBS) containing $1 \mathrm{mM} \mathrm{MgCl2}$ and were fixed with $4 \%$ paraformaldehyde in PBS for $20 \mathrm{~min}$ at room temperature. Cells were washed twice with PBS and permeabilized with $0.1 \%$ Triton X-100 in PBS for 5 min at RT. After washing twice with PBS, cells were blocked for 20 min with $5 \%$ bovine serum albumin (BSA) in PBS. Primary antibody was added in $1 \%$ BSA in PBS over night at $4{ }^{\circ} \mathrm{C}$. The next day, cells were washed twice in PBS, blocked for 20 min in $5 \%$ BSA in PBS and incubated with secondary antibody and DAPI in 1\% BSA in PBS for $1 \mathrm{~h}$ at RT in the dark. Cells were washed twice with PBS and were mounted using Fluoromount-G. Cells were imaged on an Eclipse 80i upright fluorescence microscope (Nikon).

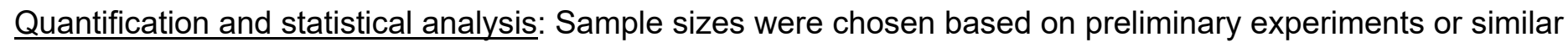
studies performed in the past. For quantification of immunoblots, a minimum of three independent experiments were performed. For quantification of immunofluorescence microscopy images, images were recorded under the same microscope settings (objective lens and illumination intensity) to ensure reliable quantification across samples and images. Merged images were created using Photoshop (Adobe), and were analyzed using ImageJ (NIH) or Image Studio (LI-COR). No samples or animals were excluded from the analysis, and quantifications were performed blindly. All data are presented as the mean \pm SEM, and represent a minimum of three independent experiments. Statistical parameters, including statistical analysis, significance, and $n$ value are reported in each figure legend. Statistical analyses were performed using Prism 8 Software (GraphPad). For statistical comparison of two groups, either two-tailed Student's $t$ test or two-way ANOVA followed by Bonferroni post hoc test was performed, as indicated in the figure legends. Based on previous studies, a normal distribution of data was assumed, with similar variance between groups that were compared. A value of $p<0.05$ was considered statistically significant.

\section{ACKNOWLEDGEMENTS}

We thank Dr. Thomas C. Südhof for providing antibodies. This work was supported by the Russian Science Foundation (Grant 19-14-00064 to V.L.B.), the Alzheimer's Association (NIRG-15-363678 to M.S.), AFAR (M.S.), the NIH (R37-AG019391 and R35-GM136686 to D.E.; 1R01-AG052505 and 1R01-NS095988 to M.S.; R01-NS102181 and R01-NS113960 to J.B.), and the Leon Levy Foundation (J.B.).

\section{AUTHOR CONTRIBUTIONS}

K.E.C, L.K., A.P., Y.N., M.S., and J.B. designed the study, performed experiments, and analyzed the data, except for the CD studies which were designed and performed by T.R. and D.E.. V.B. provided the YSyn 
antibody. J.B. wrote the manuscript with input from all authors. All authors discussed and commented on the final manuscript.

\section{DECLARATION OF INTERESTS}

The authors declare no competing interests.

\section{REFERENCES}

Abeliovich, A., Schmitz, Y., Farinas, I., Choi-Lundberg, D., Ho, W.H., Castillo, P.E., Shinsky, N., Verdugo, J.M., Armanini, M., Ryan, A., et al. (2000). Mice lacking alpha-synuclein display functional deficits in the nigrostriatal dopamine system. Neuron 25, 239-252.

Ahmad, M., Attoub, S., Singh, M.N., Martin, F.L., and El-Agnaf, O.M. (2007). Gamma-synuclein and the progression of cancer. FASEB J 21, 3419-3430.

Al-Wandi, A., Ninkina, N., Millership, S., Williamson, S.J., Jones, P.A., and Buchman, V.L. (2010). Absence of alpha-synuclein affects dopamine metabolism and synaptic markers in the striatum of aging mice. Neurobiol Aging 31, 796-804.

Benskey, M.J., Sellnow, R.C., Sandoval, I.M., Sortwell, C.E., Lipton, J.W., and Manfredsson, F.P. (2018). Silencing Alpha Synuclein in Mature Nigral Neurons Results in Rapid Neuroinflammation and Subsequent Toxicity. Front Mol Neurosci 11, 36.

Bertoncini, C.W., Rasia, R.M., Lamberto, G.R., Binolfi, A., Zweckstetter, M., Griesinger, C., and Fernandez, C.O. (2007). Structural characterization of the intrinsically unfolded protein beta-synuclein, a natural negative regulator of alpha-synuclein aggregation. J Mol Biol 372, 708-722.

Biere, A.L., Wood, S.J., Wypych, J., Steavenson, S., Jiang, Y., Anafi, D., Jacobsen, F.W., Jarosinski, M.A., Wu, G.M., Louis, J.C., et al. (2000). Parkinson's disease-associated alpha-synuclein is more fibrillogenic than beta- and gamma-synuclein and cannot cross-seed its homologs. J Biol Chem 275, 34574-34579.

Brown, J.W., Buell, A.K., Michaels, T.C., Meisl, G., Carozza, J., Flagmeier, P., Vendruscolo, M., Knowles, T.P., Dobson, C.M., and Galvagnion, C. (2016). beta-Synuclein suppresses both the initiation and amplification steps of alpha-synuclein aggregation via competitive binding to surfaces. Sci Rep 6, 36010 .

Buchman, V.L., Adu, J., Pinon, L.G., Ninkina, N.N., and Davies, A.M. (1998a). Persyn, a member of the synuclein family, influences neurofilament network integrity. Nat Neurosci 1, 101-103.

Buchman, V.L., Hunter, H.J., Pinon, L.G., Thompson, J., Privalova, E.M., Ninkina, N.N., and Davies, A.M. (1998b). Persyn, a member of the synuclein family, has a distinct pattern of expression in the developing nervous system. J Neurosci 18, 9335-9341.

Burre, J., Beckhaus, T., Schagger, H., Corvey, C., Hofmann, S., Karas, M., Zimmermann, H., and Volknandt, W. (2006). Analysis of the synaptic vesicle proteome using three gel-based protein separation techniques. Proteomics 6, 6250-6262.

Burre, J., Sharma, M., and Sudhof, T.C. (2012). Systematic mutagenesis of alpha-synuclein reveals distinct sequence requirements for physiological and pathological activities. J Neurosci 32, 15227-15242. 
Burre, J., Sharma, M., and Sudhof, T.C. (2014). alpha-Synuclein assembles into higher-order multimers upon membrane binding to promote SNARE complex formation. Proc Natl Acad Sci U S A 111, E4274-4283.

Burre, J., Sharma, M., and Sudhof, T.C. (2015). Definition of a molecular pathway mediating alpha-synuclein neurotoxicity. J Neurosci 35, 5221-5232.

Burré, J., Sharma, M., Tsetsenis, T., Buchman, V., Etherton, M.R., and Sudhof, T.C. (2010). Alpha-synuclein promotes SNARE-complex assembly in vivo and in vitro. Science 329, 1663-1667.

Burre, J., Vivona, S., Diao, J., Sharma, M., Brunger, A.T., and Sudhof, T.C. (2013). Properties of native brain alpha-synuclein. Nature 498, E4-6; discussion E6-7.

Cabin, D.E., Shimazu, K., Murphy, D., Cole, N.B., Gottschalk, W., Mcllwain, K.L., Orrison, B., Chen, A., Ellis, C.E., Paylor, R., et al. (2002). Synaptic vesicle depletion correlates with attenuated synaptic responses to prolonged repetitive stimulation in mice lacking alpha-synuclein. J Neurosci 22, 8797-8807.

Chandra, S., Fornai, F., Kwon, H.B., Yazdani, U., Atasoy, D., Liu, X., Hammer, R.E., Battaglia, G., German, D.C., Castillo, P.E., and Sudhof, T.C. (2004). Double-knockout mice for alpha- and beta-synucleins: effect on synaptic functions. Proc Natl Acad Sci U S A 101, 14966-14971.

Chandra, S., Gallardo, G., Fernandez-Chacon, R., Schluter, O.M., and Sudhof, T.C. (2005). Alpha-synuclein cooperates with CSPalpha in preventing neurodegeneration. Cell 123, 383-396.

Clayton, D.F., and George, J.M. (1999). Synucleins in synaptic plasticity and neurodegenerative disorders. J Neurosci Res 58, 120-129.

Collier, T.J., Redmond, D.E., Jr., Steece-Collier, K., Lipton, J.W., and Manfredsson, F.P. (2016). Is AlphaSynuclein Loss-of-Function a Contributor to Parkinsonian Pathology? Evidence from Non-human Primates.

Front Neurosci 10, 12.

Connor-Robson, N., Peters, O.M., Millership, S., Ninkina, N., and Buchman, V.L. (2016). Combinational losses of synucleins reveal their differential requirements for compensating age-dependent alterations in motor behavior and dopamine metabolism. Neurobiol Aging 46, 107-112.

da Costa, C.A., Masliah, E., and Checler, F. (2003). Beta-synuclein displays an antiapoptotic p53-dependent phenotype and protects neurons from 6-hydroxydopamine-induced caspase 3 activation: cross-talk with alphasynuclein and implication for Parkinson's disease. J Biol Chem 278, 37330-37335.

Davidson, W.S., Jonas, A., Clayton, D.F., and George, J.M. (1998). Stabilization of alpha-synuclein secondary structure upon binding to synthetic membranes. J Biol Chem 273, 9443-9449.

Diao, J., Burre, J., Vivona, S., Cipriano, D.J., Sharma, M., Kyoung, M., Sudhof, T.C., and Brunger, A.T. (2013). Native alpha-synuclein induces clustering of synaptic-vesicle mimics via binding to phospholipids and synaptobrevin-2/VAMP2. Elife 2, e00592.

Ducas, V.C., and Rhoades, E. (2012). Quantifying interactions of beta-synuclein and gamma-synuclein with model membranes. J Mol Biol 423, 528-539.

Fortin, D.L., Nemani, V.M., Voglmaier, S.M., Anthony, M.D., Ryan, T.A., and Edwards, R.H. (2005). Neural activity controls the synaptic accumulation of alpha-synuclein. J Neurosci 25, 10913-10921. 
Galvin, J.E., Giasson, B., Hurtig, H.I., Lee, V.M., and Trojanowski, J.Q. (2000). Neurodegeneration with brain iron accumulation, type 1 is characterized by alpha-, beta-, and gamma-synuclein neuropathology. Am J Pathol 157, 361-368.

Galvin, J.E., Uryu, K., Lee, V.M., and Trojanowski, J.Q. (1999). Axon pathology in Parkinson's disease and Lewy body dementia hippocampus contains alpha-, beta-, and gamma-synuclein. Proc Natl Acad Sci U S A 96, $13450-13455$.

George, J.M. (2002). The synucleins. Genome Biol 3, REVIEWS3002.

Gorbatyuk, O.S., Li, S., Nash, K., Gorbatyuk, M., Lewin, A.S., Sullivan, L.F., Mandel, R.J., Chen, W., Meyers, C., Manfredsson, F.P., and Muzyczka, N. (2010). In vivo RNAi-mediated alpha-synuclein silencing induces nigrostriatal degeneration. Mol Ther 18, 1450-1457.

Greten-Harrison, B., Polydoro, M., Morimoto-Tomita, M., Diao, L., Williams, A.M., Nie, E.H., Makani, S., Tian, N., Castillo, P.E., Buchman, V.L., and Chandra, S.S. (2010). alphabetagamma-Synuclein triple knockout mice reveal age-dependent neuronal dysfunction. Proc Natl Acad Sci U S A 107, 19573-19578.

Hashimoto, M., Rockenstein, E., Mante, M., Mallory, M., and Masliah, E. (2001). beta-Synuclein inhibits alphasynuclein aggregation: a possible role as an anti-parkinsonian factor. Neuron 32, 213-223.

Hawrylycz, M.J., Lein, E.S., Guillozet-Bongaarts, A.L., Shen, E.H., Ng, L., Miller, J.A., van de Lagemaat, L.N., Smith, K.A., Ebbert, A., Riley, Z.L., et al. (2012). An anatomically comprehensive atlas of the adult human brain transcriptome. Nature 489, 391-399.

Iwai, A., Masliah, E., Yoshimoto, M., Ge, N., Flanagan, L., de Silva, H.A., Kittel, A., and Saitoh, T. (1995). The precursor protein of non-A beta component of Alzheimer's disease amyloid is a presynaptic protein of the central nervous system. Neuron 14, 467-475.

Jain, M.K., Singh, P., Roy, S., and Bhat, R. (2018). Comparative Analysis of the Conformation, Aggregation, Interaction, and Fibril Morphologies of Human alpha-, beta-, and gamma-Synuclein Proteins. Biochemistry 57, 3830-3848.

Jakes, R., Spillantini, M.G., and Goedert, M. (1994). Identification of two distinct synucleins from human brain. FEBS Lett 345, 27-32.

Jakowec, M.W., Donaldson, D.M., Barba, J., and Petzinger, G.M. (2001). Postnatal expression of alphasynuclein protein in the rodent substantia nigra and striatum. Dev Neurosci 23, 91-99.

Janowska, M.K., Wu, K.P., and Baum, J. (2015). Unveiling transient protein-protein interactions that modulate inhibition of alpha-synuclein aggregation by beta-synuclein, a pre-synaptic protein that co-localizes with alphasynuclein. Sci Rep 5, 15164.

Jeannotte, A.M., McCarthy, J.G., Redei, E.E., and Sidhu, A. (2009). Desipramine modulation of alpha-, gamma-synuclein, and the norepinephrine transporter in an animal model of depression.

Neuropsychopharmacology 34, 987-998.

Ji, H., Liu, Y.E., Jia, T., Wang, M., Liu, J., Xiao, G., Joseph, B.K., Rosen, C., and Shi, Y.E. (1997). Identification of a breast cancer-specific gene, BCSG1, by direct differential cDNA sequencing. Cancer Res 57, 759-764. 
Kahle, P.J., Neumann, M., Ozmen, L., Muller, V., Jacobsen, H., Schindzielorz, A., Okochi, M., Leimer, U., van Der Putten, H., Probst, A., et al. (2000). Subcellular localization of wild-type and Parkinson's diseaseassociated mutant alpha -synuclein in human and transgenic mouse brain. J Neurosci 20, 6365-6373. Kuhn, M., Haebig, K., Bonin, M., Ninkina, N., Buchman, V.L., Poths, S., and Riess, O. (2007). Whole genome expression analyses of single- and double-knock-out mice implicate partially overlapping functions of alphaand gamma-synuclein. Neurogenetics 8,71-81.

Lautenschlager, J., Stephens, A.D., Fusco, G., Strohl, F., Curry, N., Zacharopoulou, M., Michel, C.H., Laine, R., Nespovitaya, N., Fantham, M., et al. (2018). C-terminal calcium binding of alpha-synuclein modulates synaptic vesicle interaction. Nat Commun 9, 712.

Lavedan, C. (1998). The synuclein family. Genome Res 8, 871-880.

Lavedan, C., Leroy, E., Dehejia, A., Buchholtz, S., Dutra, A., Nussbaum, R.L., and Polymeropoulos, M.H. (1998). Identification, localization and characterization of the human gamma-synuclein gene. Hum Genet 103 , 106-112.

Lein, E.S., Hawrylycz, M.J., Ao, N., Ayres, M., Bensinger, A., Bernard, A., Boe, A.F., Boguski, M.S., Brockway, K.S., Byrnes, E.J., et al. (2007). Genome-wide atlas of gene expression in the adult mouse brain. Nature 445 , 168-176.

Markopoulou, K., Biernacka, J.M., Armasu, S.M., Anderson, K.J., Ahlskog, J.E., Chase, B.A., Chung, S.J., Cunningham, J.M., Farrer, M., Frigerio, R., and Maraganore, D.M. (2014). Does alpha-synuclein have a dual and opposing effect in preclinical vs. clinical Parkinson's disease? Parkinsonism Relat Disord 20, 584-589; discussion 584.

Maroteaux, L., Campanelli, J.T., and Scheller, R.H. (1988). Synuclein: a neuron-specific protein localized to the nucleus and presynaptic nerve terminal. J Neurosci 8, 2804-2815.

Maroteaux, L., and Scheller, R.H. (1991). The rat brain synucleins; family of proteins transiently associated with neuronal membrane. Brain Res Mol Brain Res 11, 335-343.

Middleton, E.R., and Rhoades, E. (2010). Effects of curvature and composition on alpha-synuclein binding to lipid vesicles. Biophys J 99, 2279-2288.

Mori, F., Tanji, K., Yoshimoto, M., Takahashi, H., and Wakabayashi, K. (2002). Immunohistochemical comparison of alpha- and beta-synuclein in adult rat central nervous system. Brain Res 941, 118-126. Murphy, D.D., Rueter, S.M., Trojanowski, J.Q., and Lee, V.M. (2000). Synucleins are developmentally expressed, and alpha-synuclein regulates the size of the presynaptic vesicular pool in primary hippocampal neurons. J Neurosci 20, 3214-3220.

Nakajo, S., Tsukada, K., Omata, K., Nakamura, Y., and Nakaya, K. (1993). A new brain-specific 14-kDa protein is a phosphoprotein. Its complete amino acid sequence and evidence for phosphorylation. Eur $\mathrm{J}$ Biochem 217, 1057-1063. 
Nguyen, J.V., Soto, I., Kim, K.Y., Bushong, E.A., Oglesby, E., Valiente-Soriano, F.J., Yang, Z., Davis, C.H., Bedont, J.L., Son, J.L., et al. (2011). Myelination transition zone astrocytes are constitutively phagocytic and have synuclein dependent reactivity in glaucoma. Proc Natl Acad Sci U S A 108, 1176-1181.

Ninkina, N., Papachroni, K., Robertson, D.C., Schmidt, O., Delaney, L., O'Neill, F., Court, F., Rosenthal, A., Fleetwood-Walker, S.M., Davies, A.M., and Buchman, V.L. (2003). Neurons expressing the highest levels of gamma-synuclein are unaffected by targeted inactivation of the gene. Mol Cell Biol 23, 8233-8245.

Ninkina, N., Peters, O., Millership, S., Salem, H., van der Putten, H., and Buchman, V.L. (2009). Gammasynucleinopathy: neurodegeneration associated with overexpression of the mouse protein. Hum Mol Genet 18, 1779-1794.

Ninkina, N., Peters, O.M., Connor-Robson, N., Lytkina, O., Sharfeddin, E., and Buchman, V.L. (2012).

Contrasting effects of alpha-synuclein and gamma-synuclein on the phenotype of cysteine string protein alpha (CSPalpha) null mutant mice suggest distinct function of these proteins in neuronal synapses. J Biol Chem 287, 44471-44477.

Ninkina, N., Tarasova, T.V., Chaprov, K.D., Roman, A.Y., Kukharsky, M.S., Kolik, L.G., Ovchinnikov, R., Ustyugov, A.A., Durnev, A.D., and Buchman, V.L. (2020). Alterations in the nigrostriatal system following conditional inactivation of alpha-synuclein in neurons of adult and aging mice. Neurobiol Aging 91, 76-87. Ninkina, N.N., Alimova-Kost, M.V., Paterson, J.W., Delaney, L., Cohen, B.B., Imreh, S., Gnuchev, N.V., Davies, A.M., and Buchman, V.L. (1998). Organization, expression and polymorphism of the human persyn gene. Hum Mol Genet 7, 1417-1424.

Nishioka, K., Wider, C., Vilarino-Guell, C., Soto-Ortolaza, A.I., Lincoln, S.J., Kachergus, J.M., Jasinska-Myga, B., Ross, O.A., Rajput, A., Robinson, C.A., et al. (2010). Association of alpha-, beta-, and gamma-Synuclein with diffuse lewy body disease. Arch Neurol 67, 970-975.

Papachroni, K., Ninkina, N., Wanless, J., Kalofoutis, A.T., Gnuchev, N.V., and Buchman, V.L. (2005).

Peripheral sensory neurons survive in the absence of alpha- and gamma-synucleins. J Mol Neurosci 25, 157164.

Park, J.Y., and Lansbury, P.T., Jr. (2003). Beta-synuclein inhibits formation of alpha-synuclein protofibrils: a possible therapeutic strategy against Parkinson's disease. Biochemistry 42, 3696-3700.

Peters, O.M., Millership, S., Shelkovnikova, T.A., Soto, I., Keeling, L., Hann, A., Marsh-Armstrong, N., Buchman, V.L., and Ninkina, N. (2012). Selective pattern of motor system damage in gamma-synuclein transgenic mice mirrors the respective pathology in amyotrophic lateral sclerosis. Neurobiol Dis 48, $124-131$. Rivers, R.C., Kumita, J.R., Tartaglia, G.G., Dedmon, M.M., Pawar, A., Vendruscolo, M., Dobson, C.M., and Christodoulou, J. (2008). Molecular determinants of the aggregation behavior of alpha- and beta-synuclein. Protein Sci 17, 887-898.

Robertson, D.C., Schmidt, O., Ninkina, N., Jones, P.A., Sharkey, J., and Buchman, V.L. (2004). Developmental loss and resistance to MPTP toxicity of dopaminergic neurones in substantia nigra pars compacta of gammasynuclein, alpha-synuclein and double alpha/gamma-synuclein null mutant mice. J Neurochem 89, 1126-1136. 
Sanjeev, A., and Mattaparthi, V.S.K. (2017). Investigation on the Molecular Interactions Stabilizing the Structure of alpha-synuclein Fibril: An In silico Study. Cent Nerv Syst Agents Med Chem 17, 209-218. Schluter, O.M., Fornai, F., Alessandri, M.G., Takamori, S., Geppert, M., Jahn, R., and Sudhof, T.C. (2003). Role of alpha-synuclein in 1-methyl-4-phenyl-1,2,3,6-tetrahydropyridine-induced parkinsonism in mice. Neuroscience 118, 985-1002.

Scott, D., and Roy, S. (2012). alpha-Synuclein inhibits intersynaptic vesicle mobility and maintains recyclingpool homeostasis. J Neurosci 32, 10129-10135.

Senior, S.L., Ninkina, N., Deacon, R., Bannerman, D., Buchman, V.L., Cragg, S.J., and Wade-Martins, R. (2008). Increased striatal dopamine release and hyperdopaminergic-like behaviour in mice lacking both alphasynuclein and gamma-synuclein. Eur J Neurosci 27, 947-957.

Sharma, K., Mehra, S., Sawner, A.S., Markam, P.S., Panigrahi, R., Navalkar, A., Chatterjee, D., Kumar, R., Kadu, P., Patel, K., et al. (2020). Effect of Disease-Associated P123H and V70M Mutations on beta-Synuclein Fibrillation. ACS Chem Neurosci 11, 2836-2848.

Sharma, M., Burre, J., Bronk, P., Zhang, Y., Xu, W., and Sudhof, T.C. (2012). CSPalpha knockout causes neurodegeneration by impairing SNAP-25 function. EMBO J 31, 829-841.

Sharma, M., Burre, J., and Sudhof, T.C. (2011). CSPalpha promotes SNARE-complex assembly by chaperoning SNAP-25 during synaptic activity. Nat Cell Biol 13, 30-39.

Spillantini, M.G., Schmidt, M.L., Lee, V.M., Trojanowski, J.Q., Jakes, R., and Goedert, M. (1997). Alphasynuclein in Lewy bodies. Nature 388, 839-840.

Sun, J., Wang, L., Bao, H., Premi, S., Das, U., Chapman, E.R., and Roy, S. (2019). Functional cooperation of alpha-synuclein and VAMP2 in synaptic vesicle recycling. Proc Natl Acad Sci U S A 116, 11113-11115.

Sung, Y.H., and Eliezer, D. (2006). Secondary structure and dynamics of micelle bound beta- and gammasynuclein. Protein Sci 15, 1162-1174.

Surgucheva, I., McMahan, B., Ahmed, F., Tomarev, S., Wax, M.B., and Surguchov, A. (2002). Synucleins in glaucoma: implication of gamma-synuclein in glaucomatous alterations in the optic nerve. J Neurosci Res 68, 97-106.

Surguchov, A., Palazzo, R.E., and Surgucheva, I. (2001). Gamma synuclein: subcellular localization in neuronal and non-neuronal cells and effect on signal transduction. Cell Motil Cytoskeleton 49, 218-228. Tao-Cheng, J.H. (2006). Activity-related redistribution of presynaptic proteins at the active zone. Neuroscience 141, 1217-1224.

Tenreiro, S., Rosado-Ramos, R., Gerhardt, E., Favretto, F., Magalhaes, F., Popova, B., Becker, S., Zweckstetter, M., Braus, G.H., and Outeiro, T.F. (2016). Yeast reveals similar molecular mechanisms underlying alpha- and beta-synuclein toxicity. Hum Mol Genet 25, 275-290.

Tsigelny, I.F., Bar-On, P., Sharikov, Y., Crews, L., Hashimoto, M., Miller, M.A., Keller, S.H., Platoshyn, O., Yuan, J.X., and Masliah, E. (2007). Dynamics of alpha-synuclein aggregation and inhibition of pore-like oligomer development by beta-synuclein. FEBS J 274, 1862-1877. 
Ueda, K., Fukushima, H., Masliah, E., Xia, Y., Iwai, A., Yoshimoto, M., Otero, D.A., Kondo, J., Ihara, Y., and Saitoh, T. (1993). Molecular cloning of cDNA encoding an unrecognized component of amyloid in Alzheimer disease. Proc Natl Acad Sci U S A 90, 11282-11286.

Ueda, K., Saitoh, T., and Mori, H. (1994). Tissue-dependent alternative splicing of mRNA for NACP, the precursor of non-A beta component of Alzheimer's disease amyloid. Biochem Biophys Res Commun 205, 1366-1372.

Uversky, V.N., Li, J., Souillac, P., Millett, I.S., Doniach, S., Jakes, R., Goedert, M., and Fink, A.L. (2002). Biophysical properties of the synucleins and their propensities to fibrillate: inhibition of alpha-synuclein assembly by beta- and gamma-synucleins. J Biol Chem 277, 11970-11978.

Van de Vondel, E., Baatsen, P., Van Elzen, R., Lambeir, A.M., Keiderling, T.A., Herrebout, W.A., and Johannessen, C. (2018). Vibrational Circular Dichroism Sheds New Light on the Competitive Effects of Crowding and beta-Synuclein on the Fibrillation Process of alpha-Synuclein. Biochemistry 57, 5989-5995. Vargas, K.J., Schrod, N., Davis, T., Fernandez-Busnadiego, R., Taguchi, Y.V., Laugks, U., Lucic, V., and Chandra, S.S. (2017). Synucleins Have Multiple Effects on Presynaptic Architecture. Cell Rep 18, 161-173. Windisch, M., Hutter-Paier, B., Rockenstein, E., Hashimoto, M., Mallory, M., and Masliah, E. (2002). Development of a new treatment for Alzheimer's disease and Parkinson's disease using anti-aggregatory betasynuclein-derived peptides. J Mol Neurosci 19, 63-69.

Yavich, L., Tanila, H., Vepsalainen, S., and Jakala, P. (2004). Role of alpha-synuclein in presynaptic dopamine recruitment. J Neurosci 24, 11165-11170. 


\section{FIGURE LEGENDS}

\section{Figure 1. Binding of recombinant synucleins to liposomes.}

(A-C) aSyn, $\beta$ Syn or $\gamma$ Syn were floated by density gradient centrifugation with synaptic vesicle mimics (30 nm diameter; composition: 36\% PC, 30\% PE, 12\% PS, 5\% PI, 7\% SM, 10\% cholesterol) or artificial small unilamellar vesicles (30 nm diameter; composition: 70\% PC, 30\% PS). Top two fractions 1 and 2 were defined as lipid-bound fractions (see Figure S1B). Flotation of synucleins with liposomes was quantified as the sum of the top 2 fractions, plotted as the percentage of total synuclein in the gradient. $(B, C)$ Same as in $(A)$, except that different molar lipid/protein ratios of small unilamellar vesicles were used. Data are means \pm SEM $\left({ }^{* * *} p<\right.$ 0.001 by Student's $\mathrm{t}$ test; $\mathrm{n}=6$ - 8 independent experiments).

(D-F) CD spectroscopy of synucleins. (D, E) Secondary structure of recombinant $\alpha$ Syn, $\beta$ Syn or $\gamma$ Syn in absence (D) or presence (E) of $30 \mathrm{~nm}$ SUVs at a molar lipid/protein ratio of 400. (F) Same as (E), except that different molar/lipid ratios were used, and signal at $222 \mathrm{~nm}$ was plotted to highlight $\alpha$-helicity (mean of $n=3$ ).

\section{Figure 2. Presynaptic localization of synucleins.}

(A, B) Brains of P40 WT mice were homogenized and half of the homogenate was subjected to subcellular fractionation to yield synaptosomes. Equal protein amount of brain homogenate and synaptosomes was separated by SDS-PAGE and analyzed by quantitative immunoblotting of the indicated protein (Syb2, synaptobrevin-2; aTub, a-tubulin; NF165, neurofilament of 165 kDa).

(C-E) Primary cortical WT mouse neurons were analyzed at 27DIV for the indicated proteins. Colocalization was quantitated using Pearson's coefficient. Data are means $\pm \operatorname{SEM}\left(\left(^{* *} p<0.01,{ }^{* * *} p<0.001\right.\right.$ by Student's $t$ test; $n=4$ brains in (A, B) and 6 independent cultures in (C-E)).

\section{Figure 3. Interaction between synucleins.}

(A) Fluorescent synuclein labeling scheme for FRET experiments. Single-cysteine substitutions were introduced into synucleins at position 8 and 96 for $\alpha$ Syn and $\gamma$ Syn, and at position 8 and 85 for $\beta$ Syn for modification with Alexa 488- or Alexa546-maleimide.

(B) Configuration of synuclein multimers (stars = labeled residues).

$(C, D)$ Emission spectra in Figure S3C-H were used for calculation of FRET signals between synucleins. Data are means $\pm \operatorname{SEM}\left({ }^{*} p<0.05,{ }^{* *} p<0.01,{ }^{* * *} p<0.001\right.$ by Student $t$ test; $n=3$ independent experiments).

\section{Figure 4. Decreased synaptic vesicle binding of $\alpha$ Syn in presence of $\beta$ Syn or $\gamma$ Syn.}

(A-D) Synaptic targeting of aSyn in absence or presence of increasing amounts of $\beta$ Syn or $\gamma$ Syn. $\alpha \beta \gamma-S y n$ triple knockout neurons were transduced with lentiviral vectors expressing aSyn only $(A)$ or aSyn with increasing amounts of $\beta$ Syn (B) or $\gamma$ Syn (C). Synaptic targeting was quantified by co-localization with synapsin and Pearson's coefficient (D). Data are means \pm SEM ( ${ }^{*} p<0.05$ by Student $t$ test; $n=3$ cultures).

$(E, F)$ Analysis of aSyn enrichment in synaptosomes. Synaptosomes were isolated from mouse brain homogenates of mice lacking $\beta$ Syn or $\gamma$ Syn via subcellular fractionation. $20 \mu \mathrm{g}$ protein of homogenate and synaptosomes were analyzed by quantitative immunoblotting to the indicated proteins (Syb2, synaptobrevin-2; 
$\alpha$ Tub, $\alpha$-tubulin; NF165, neurofilament of $165 \mathrm{kDa})$. Data are means \pm SEM $\left({ }^{* *} p<0.01,{ }^{* * *} p<0.0001\right.$ by Student $\mathrm{t}$ test; $\mathrm{n}=6-8$ mice; see also Figure S5C-E).

$(G, H)$ Co-flotation of synucleins. Liposome binding of aSyn was analyzed in absence or presence of equal amounts of $\beta$ Syn or $\gamma$ Syn by a flotation assay. Flotation of $\alpha$ Syn with liposomes was quantified as the sum of the top 2 fractions, plotted as the percentage of total synuclein in the gradient. Data are means \pm SEM $\left({ }^{*} p<\right.$ $0.05,{ }^{* *} p<0.01$ by Student's t test; $n=7-15$ independent experiments).

(I) Proposed model of the effect of $\beta S y n$ or $\gamma$ Syn on aSyn function. Via hetero-multimerization, $\beta$ Syn and $\gamma S y n$ reduce synaptic vesicle-bound aSyn which leads to a reduction in aSyn's physiological activity to mediate SNARE-complex assembly, synaptic vesicle clustering and neurotransmitter release. 

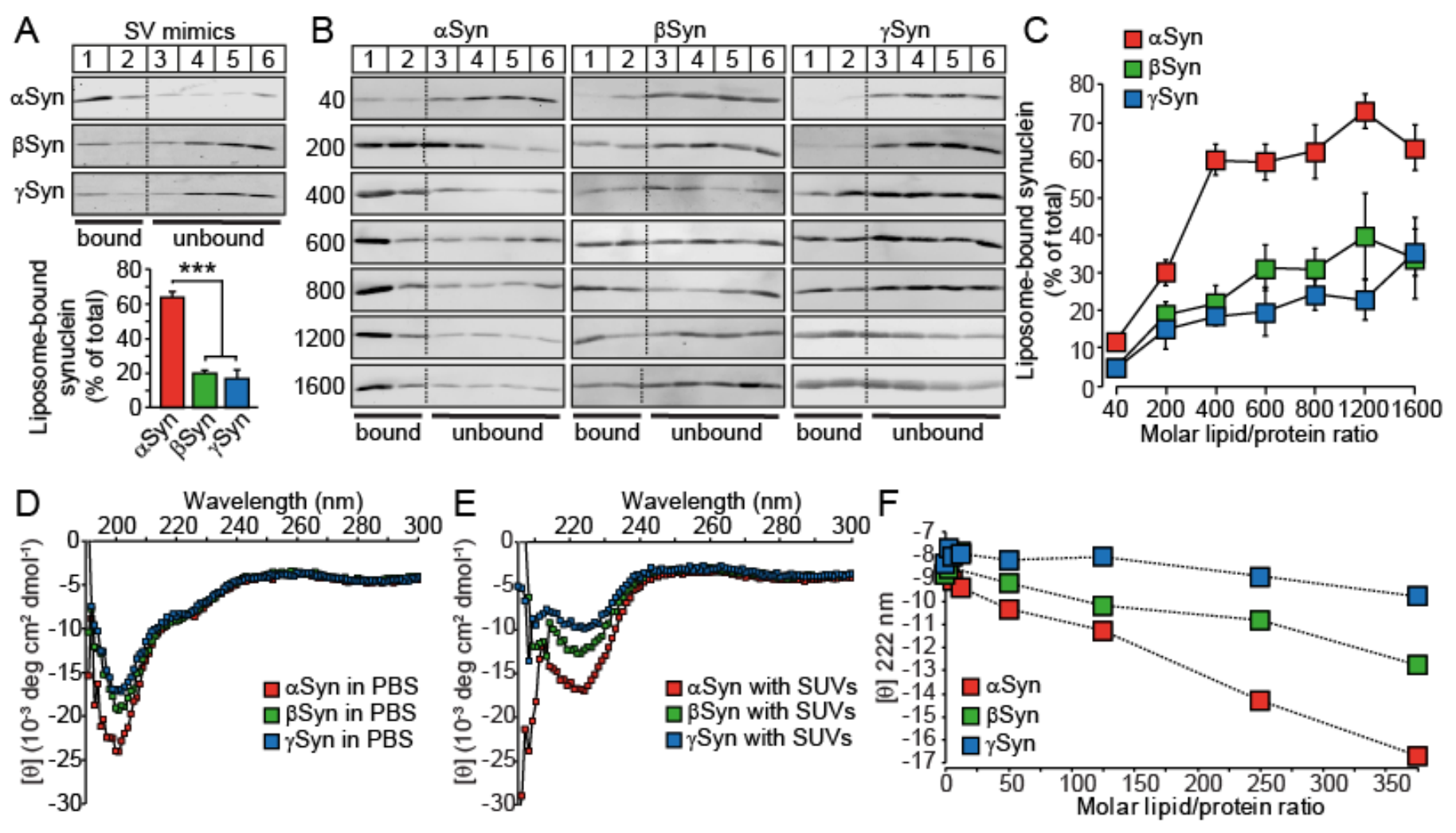

Carnazza et al

Figure 1 


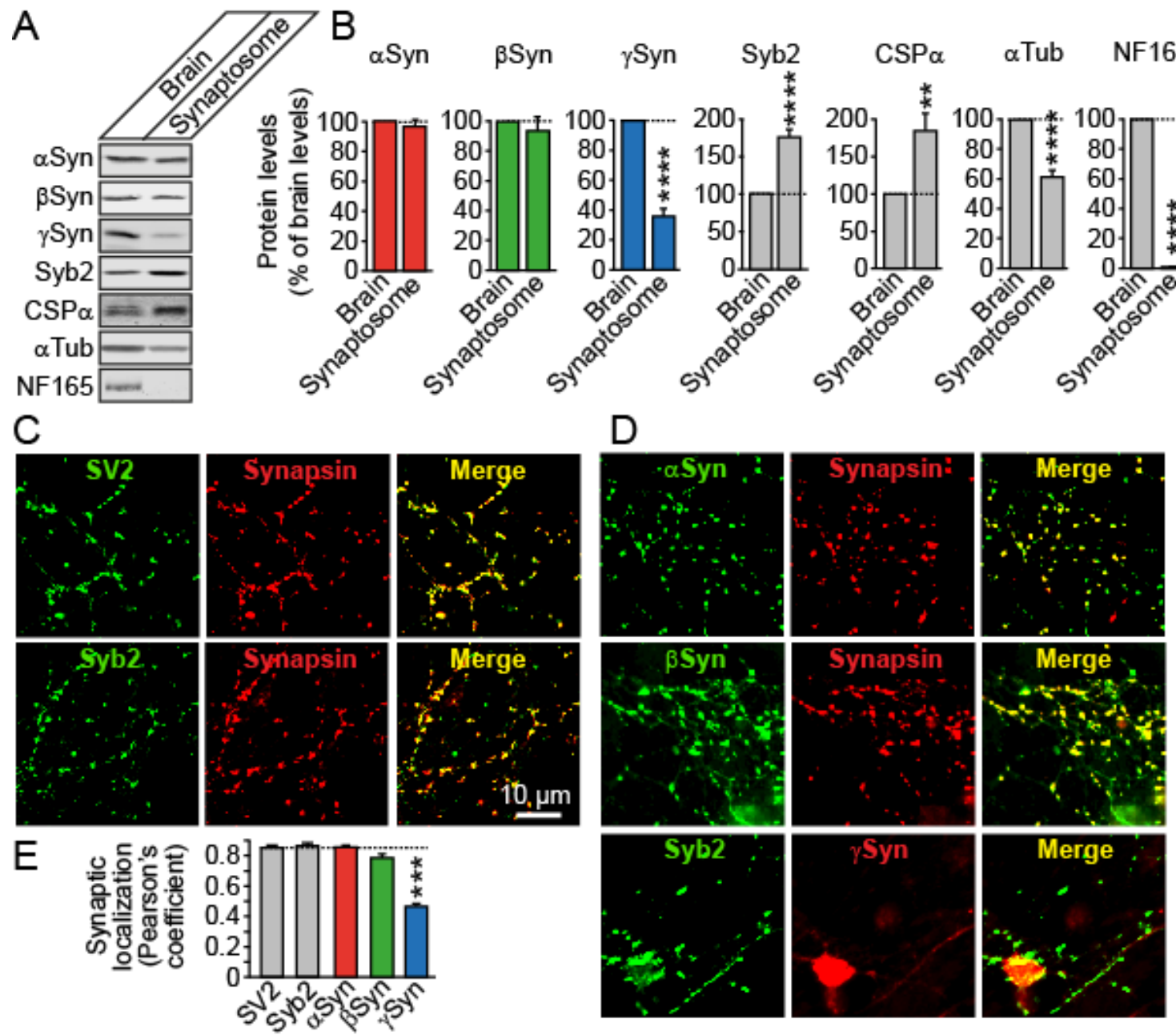

Carnazza et al

Figure 2 
A

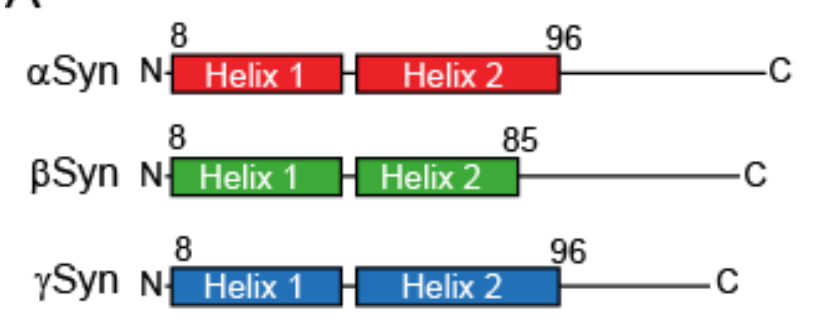

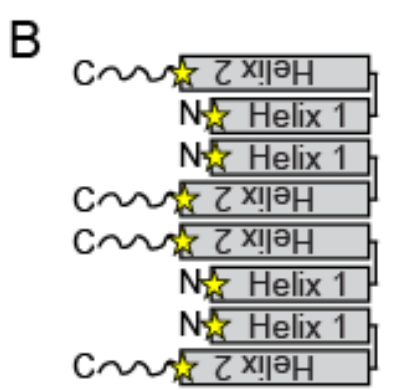

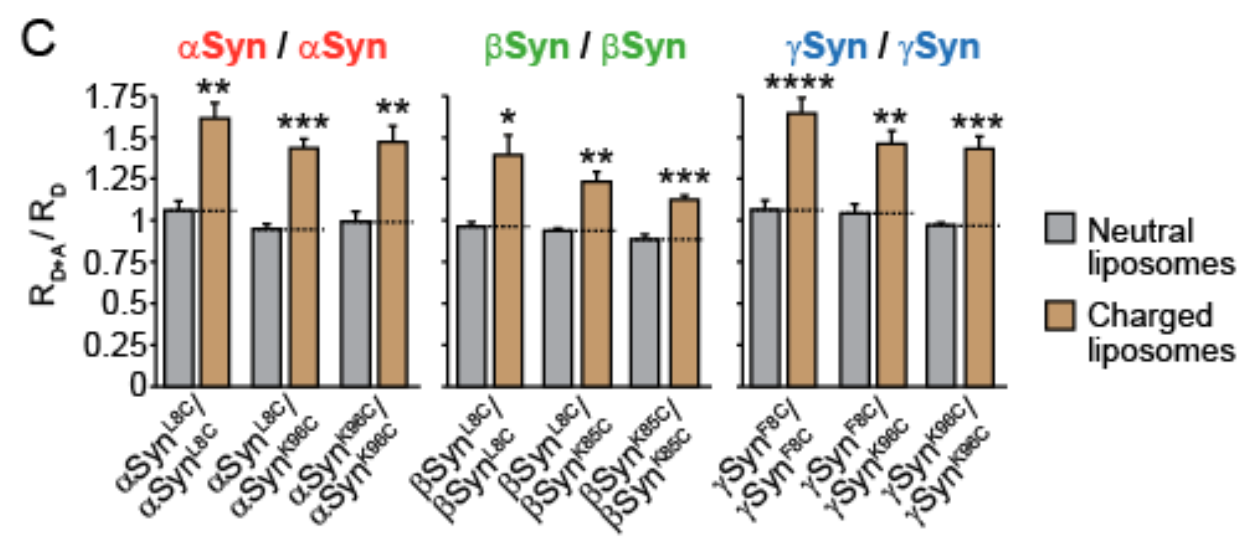

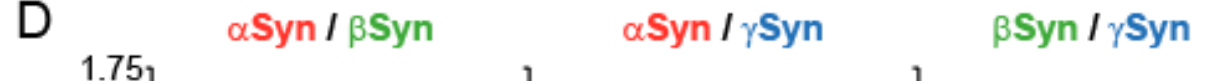

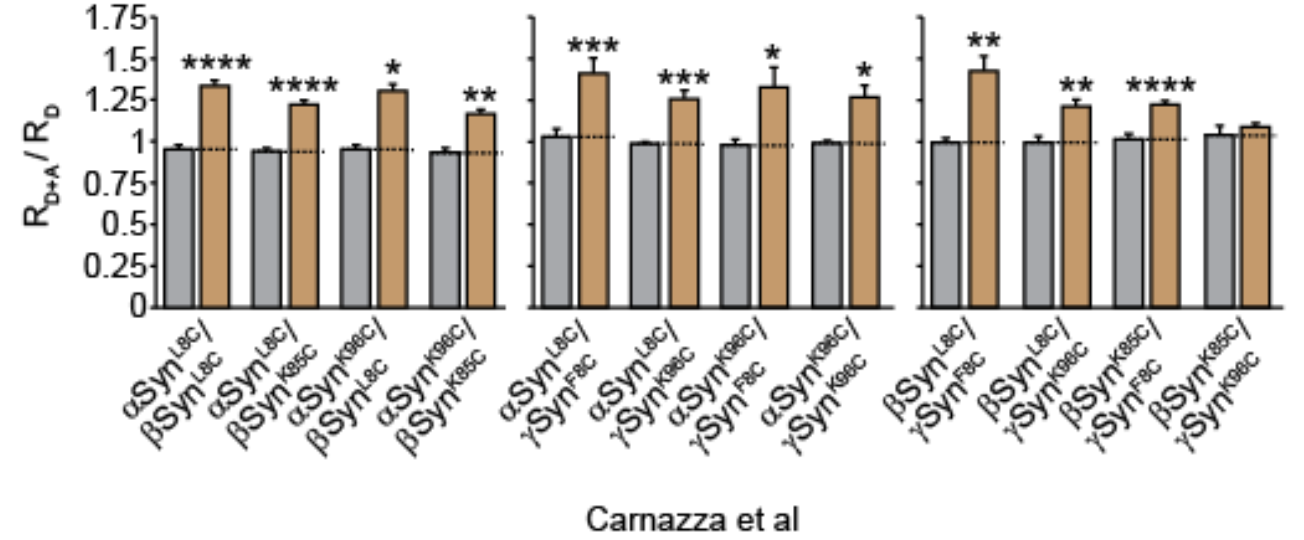

Figure 3 
A

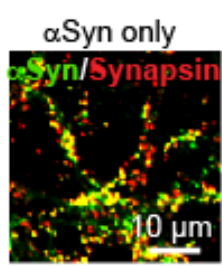

$\alpha \beta \gamma$ Syn KO

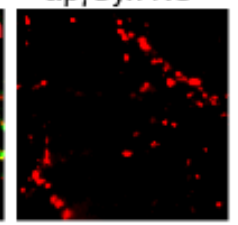

D

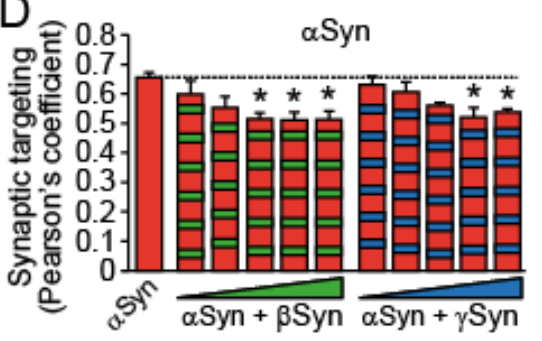

B
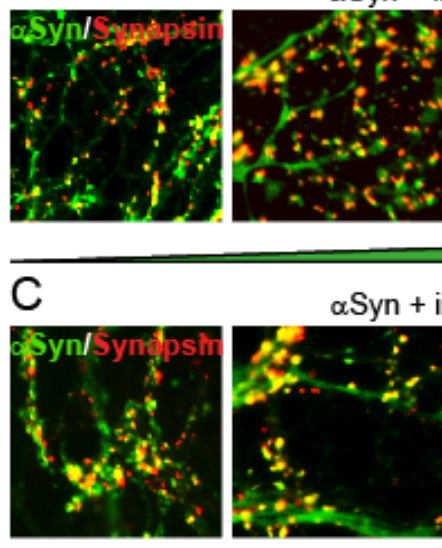

$\alpha$ Syn + increasing amounts of $\beta$ Syn
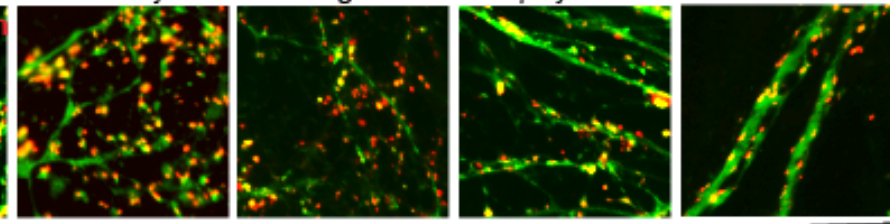

G
$\mathrm{H}$

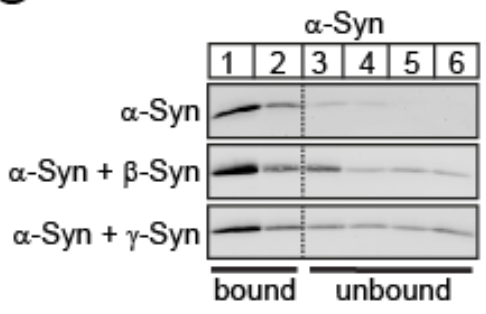

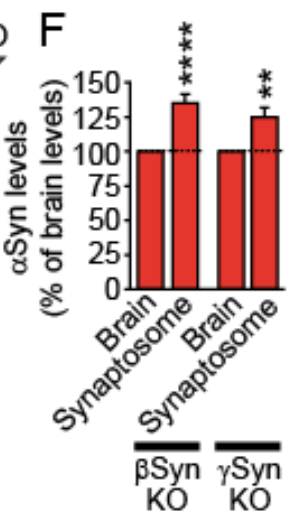

E

$\alpha \operatorname{Syn} \underset{ }{\longrightarrow \text { N.A. }}$

Syb2

$\operatorname{csP} \alpha$

$\alpha$ Tub

NF165 $\gamma$ Syn

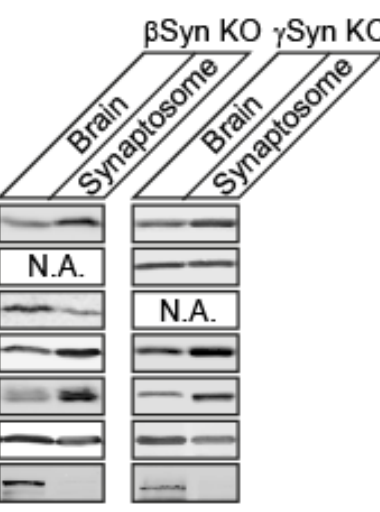

$\alpha$ Syn only

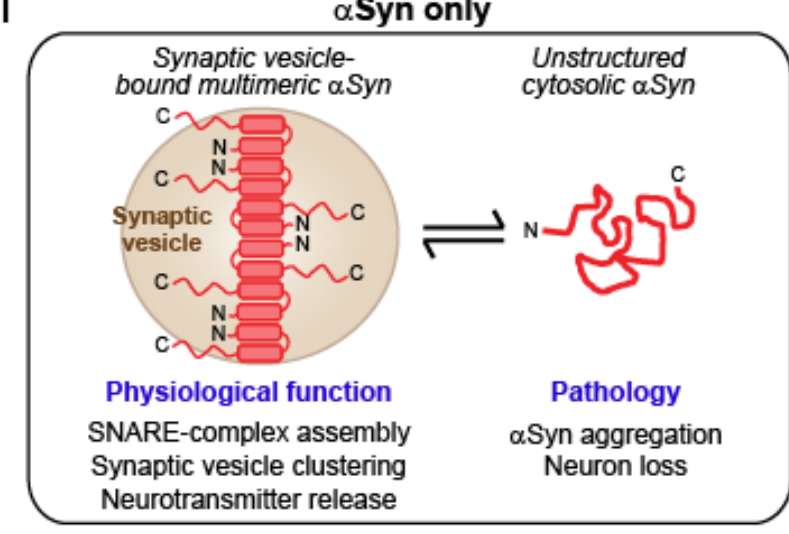

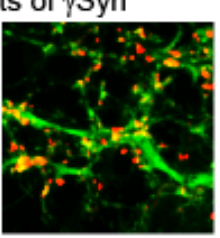
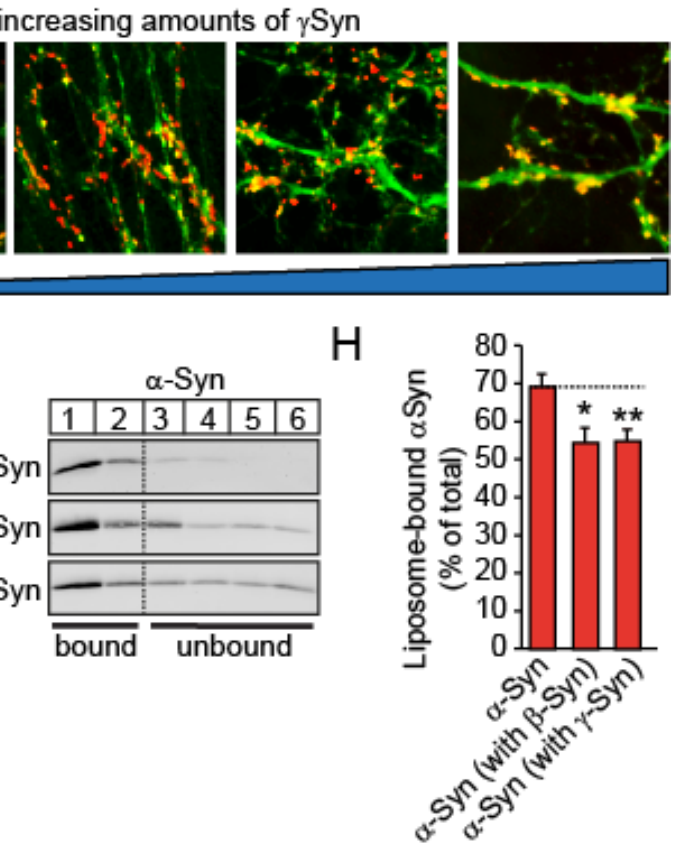

$\alpha$ Syn in presence of $\beta$ Syn or $\gamma$ Syn

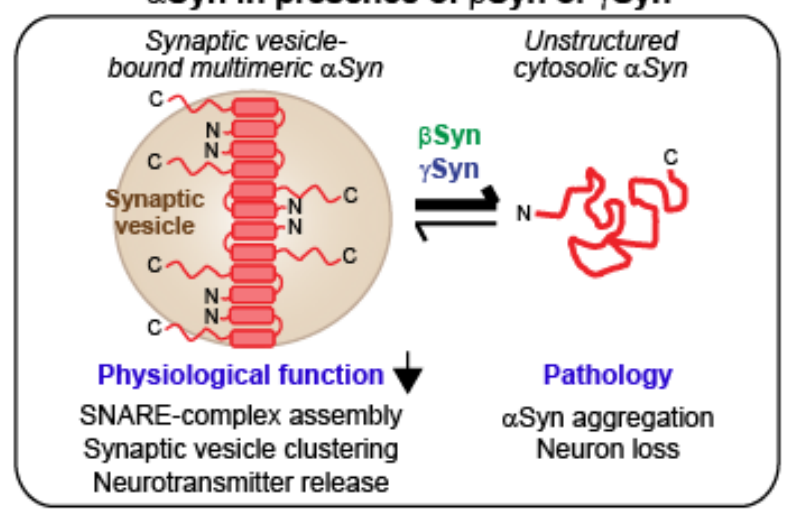

Carnazza et al

Figure 4 